\title{
Pharmacology
}

\section{Note from the Publishers}

It is a pleasure for the publishers to acknowledge more than 30 years of distinguished, devoted service by Prof. Elliot S. Vesell as editor of Pharmacology. In recognition of that service, as well as his retirement not only as editor but also as the Founding Chairman of the Department of Pharmacology at the Pennsylvania State University College of Medicine after 32 years, this special issue of Pharmacology is dedicated to him. Professor Vesell has had an outstanding career in pharmacology, as investigator, educator and farsighted leader of the discipline.

An innovative researcher, Professor Vesell is considered by many to be a founding father of the field of pharmacogenetics. His meticulously designed twin studies in healthy human subjects established that large pharmacokinetic variations among individuals for commonly used drugs were genetically controlled. This work and his family studies have led to new insights and helped provide a foundation for the emerging field of pharmacogenomics.

Prof. Vesell has received numerous awards. Among these are the American Society for Pharmacology and Experimental Therapeutics Award for Experimental Therapeutics in 1971 and its Harry Gold Award in 1985. He served as President (1980-1982) of the American College of Clinical Pharmacology, President (1980-1982) of the Association for Medical School Pharmacology, and Treasurer (1994-1997) of the Society for Experimental Biology and Medicine, from which he received the Meltzer Award in 1967. Prof. Vesell was also Secretary-Treasurer of the American Society for Pharmacology and Experimental Therapeutics (1995-1997). He is a member of the American Society for Clinical Pharmacology and Therapeutics, from which he received their major prize, the

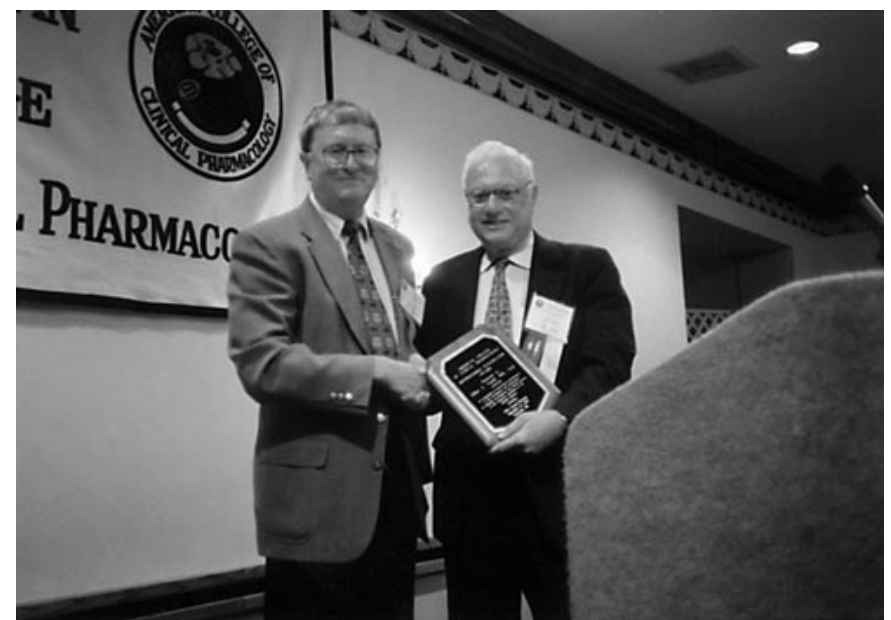

Fig. 1. Prof. Elliot S. Vesell (right) receiving the Distinguished Investigator Award of the American College of Clinical Pharmacology, on September 16, 1999. Dr. Brian Johnson (left), Honors and Award Committee Chairman, presents this award to Prof. Vesell.

Oscar B. Hunter Award in 1991, the American Society for Clinical Investigation, the Association of American Physicians, and the Royal Society of Medicine (UK). Prof. Vesell received honorary doctorate degrees from the Philadelphia College of Pharmacy and Sciences (1988) and Philipps University, Marburg (1992). Most recently, in 1999, Prof. Vesell received the Distinguished Investigator Award of the American College of Clinical Pharmacology (fig. 1).

Dr. h.c. Thomas Karger For the Publishers

\section{KARGER}

(c) 2000 S. Karger AG, Basel

Fax +41613061234

E-Mail karger@karger.ch www. karger.com
Accessible online at: www. karger.com/journals/pha 